\title{
O LAICISMO POLÍTICO NA MONARQUIA DE DANTE
}

\author{
Pedro Calafate
}

Universidade de Lisboa

\begin{abstract}
A par do culto da poesia amorosa e do entusiasmo perante a ciência moral como meio de realização da perfeição humana, o desejo de uma reforma político-religiosa foi um dos ensejos mais profundos do pensamento de Dante, como fica patente na Divina Comédia, em que a reforma da sociedade se lhe impunha como imperativo de justiça, a mais nobre de todas as virtudes, e sobretudo na Monarquia, escrita em torno do ano de 1314 , onde expõe mais detidamente as suas teses sobre a monarquia universal, em consonância com o ideal de perfeição humana.

Antes porém, no Convívio, Dante já se referira amplamente ao modo como encarava a Filosofia, pois nela se propõe iniciar os seus concidadãos que, devido à absorção nos cargos públicos, ficavam impedidos de se iniciarem nestas matérias e, por isso, impedidos de atingirem aquele grau de perfeição a que como seres racionais deveriam aspirar.

Como sublinhou Étienne Gilson ${ }^{1}$, para Dante a filosofia é ciência de laicos, cultivada em ordem a pôr ao alcance do homem a plena realização dos fins temporais que lhe eram próprios. A filosofia, como diz o mesmo autor, busca a realização da felicidade humana e, como tal, tenderá a convergir na ciência moral. Por isso, o Convívio é uma iniciação filosófica para as gentes do mundo, onde já se descortina a questão das relações entre a filosofia e a autoridade imperial. Por isso, também, quando se entrega à classificação das ciências, Dante estabelece uma hierarquia, elaborada em correspondência simbólica com a pluralidade dos céus e, numa progressão ascendente, eleva a moral ao mais alto grau, fazendo-a corresponder ao «cristalino», o mais digno dos céus naturais, num contexto que deixa perceber a supremacia da moral sobre a metafísica.

Para Dante, a metafísica era sem dúvida a mais nobre das ciências
\end{abstract}

1 É. Gilson, Dante et la Philosophie, Paris, 1953, p. 37.

Philosophica, 34, Lisboa, 2009, pp. 405-412 
naturalmente acessíveis ao homem, mas dominamo-la de forma deficiente e daí que, tendo em conta os destinatários dos seus textos, se inclinasse para a moral, por mais acessível e eficaz na realização dos ideias de perfeição humana.

A não descurar é também a relação entre a filosofia e a teologia, a ciência de Deus que, por ser sobrenatural na sua origem, corresponde ao décimo céu, apenas reconhecido pelos teólogos e lugar de paz, ao abrigo das discussões e opiniões dos sábios.

Mas, ao separar a teologia das outras ciências, Dante pode assim não considerar a filosofia como serva da teologia, não se tratando embora de saberes contrários. Ambas colaboram na obra comum da salvação do homem, mas para que tal suceda não necessita a filosofia de submeter-se aos ditames da teologia, bastando-lhe que exista como filosofia, na mesma linha se perspectivando as relações entre a vida activa e a vida contemplativa.

A vida de Maria é mais excelente que a de Marta, mas as virtudes de Marta eram as que se coadunavam com o género de vida dos seus concidadãos. Não que Dante rejeitasse a possibilidade de um começo de beatitude especulativa na vida terrena, simplesmente não julgava possível que atingisse plenamente o seu fim: seria obra de um anjo e não dos homens.

Estes aspectos afiguram-se importantes para compreendermos o texto que me proponho aqui analisar mais detidamente: a Monarquia, escrito na segunda década do século XIV, quando já se encontrava a redigir a sua mais conhecida obra, a Divina Comédia.

A Monarquia é um texto em que Dante revela uma decisiva orientação para o ideal de uma sociedade universal de justiça e paz (sendo importante sublinhar que já no De Vulgari Eloquentia se tinha dedicado à análise da questão da língua universal), mas sociedade universal entendida sob forma temporal e laica, diferente, por isso, do ideal medieval da cristandade. A sociedade universal que Dante persegue, na Monarquia, tinha a felicidade temporal como fim próprio e a filosofia como fundamento, sublinhando as vertentes moral e gnosiológica da política.

De facto, recorrendo às noções escolásticas de intelecto agente e intelecto possível, defende Dante que apenas a espécie humana, tomada no seu conjunto, poderia aspirar a uma actualização da potência do intelecto possível, atribuindo assim uma base gnosiológica e estritamente filosófica ao poder temporal e à monarquia universal, que teria como fim, precisamente, a actualização do intelecto possível.

A ciência política não era, como a matemática ou a geometria, uma ciência não sujeita à nossa vontade e, por isso, uma ciência que apenas poderia ser, para nós, objecto de especulação. Ao contrário, a política, 
refere-se a uma actividade subordinada à vontade humana e, por isso, é para nós objecto de especulação e também de acção e para a acção privilegiadamente se ordena. No entanto, como no âmbito da acção o princípio e causa universal reside no fim último, importava inquirir qual o fim da sociedade humana a que a política se refere.

É aqui que Dante se revela verdadeiramente inovador. A virtude suprema do homem não consiste apenas em existir, ou em ser um organismo, nem em ser animado, nem em ser sensitivo, virtudes que partilha com as diferentes ordens dos demais seres. A virtude suprema do homem está, como Dante sublinha, em receber as formas inteligíveis dos outros seres num intelecto possível, ou seja, na faculdade ou virtude da intelecção, a qual não passa de potência a acto, inteira e simultaneamente, mercê de um único indivíduo ou grupo particular, carecendo, por isso, da pluralidade existente na totalidade do género humano. É neste pilar que assenta a necessidade da monarquia universal, do império e do príncipe supremo: a monarquia universal é a condição da suprema perfeição da potência específica do homem, isto é, da virtude da intelecção, dada a necessidade desta se actualizar no conjunto da humanidade.

Por outras palavras, a capacidade de inteligir jamais será actualizada por um único homem, mas sim pelo conjunto do género humano, razão por que se torna imprescindível a paz universal, e razão, também, por que o império universal visa a realização da finalidade natural e imanente dos homens. Como se vê, Dante sublinha a tese de que a operação intelectual é a perfeição do homem, mas retira-lhe o carácter elitista de que se revestira no mundo grego.

Distanciando-se do ideal medieval da cristandade, que comportava a tese de uma subordinação complexa do poder temporal ao poder espiritual, nem por isso Dante se distancia da tese da superioridade ontológica da unidade sobre a multiplicidade, apoiando-se na tese de que o império universal é a condição política para a realização da unidade do género humano, pois que a bondade de uma ordem parcial nunca supera a bondade de uma ordem total. Além disso, o império é a condição política para que o homem melhor realize a intenção do primeiro agente, que é Deus, e se a intenção de Deus é a de que cada homem reproduza a bondade divina, na medida em que a natureza própria lho permita, segue-se que, sendo Deus a unidade perfeita, o género humano tanto mais imita Deus quanto mais se unifica. Para Dante, a unidade é a raiz do bom e a multiplicidade a raiz do mal e, por isso, tudo o que é bom é-o por aquilo mesmo que o torna uno. Diz então Dante:

«realiza, então, o género humano o máximo da unidade quando se une, inteiro, num só homem - o que só pode efectuar-se quando todo ele está sujeito a um só príncipe. Submetido a um único príncipe, fica 
portanto assimilado a Deus o mais perfeitamente possível, obedecendo, assim, à instrução divina» ${ }^{2}$

Por outro lado, determina-se também a excelência da monarquia Universal em razões de ordem prática, pois que, não tendo o monarca supremo competidores, e por tudo possuir e nada desejar, é o mais apto para o exercício da justiça, da qual nasce a paz, sendo a justiça a causa mais eficiente da paz.

E se aqui se assinala o fundamento ético do poder e o primado da ética sobre a política, também por isso Dante se faz eco da concepção clássica do personalismo régio, à luz da qual sustenta a necessidade de ter que estar perfeitamente ordenado quem que deseja ordenar os outros. Neste caso, o Monarca Universal é o que tem menos disposições hostis, pois que ao tudo possuir, pouco ou nada the resta para desejar, ficando ao abrigo da cupidez.

Todavia, ao sublinhar a supremacia ontológica da unidade e o império como condição política da sua realização na terra, Dante não deixa de considerar a imensa diversidade de que se compõe o género humano nas suas condições práticas de existência, sendo deveras interessante a sua tese de que o género humano apenas deve ser governado pelo monarca universal «naqueles pontos comuns a todos os homens, e ser assim encaminhado à paz por uma única lei, a qual os príncipes particulares devem receber do Monarca ${ }^{3}$. De facto, para além dos pontos comuns, importava, como diz Dante, reconhecer que «têm as nações, os reinos e as cidades propriedades diversas que exigem um governo com leis correlativamente diversas $\rangle^{4}$. Como se estabelece então a relação entre o monarca universal e os príncipes particulares das diversas nações, dos diversos climas, das diferentes partes da terra. O modelo gnosiológico volta a prevalecer: «tal como o intelecto prático recebe do intelecto especulativo a proposição maior, que comanda a conclusão prática para, subsumindo nela a conclusão particular, concluir em tal acção» ${ }^{5}$, também assim e nos mesmos termos se deveria perspectivar a relação entre o Imperador Universal e os príncipes particulares.

São estes os fundamentos filosóficos da monarquia universal, havendo agora a necessidade de analisar o candente problema das relações entre o monarca universal e o pontífice romano, segundo pilar do laicismo político de Dante.

\footnotetext{
2 Dante Alighieri, Tutte le Oppere, a cura de Fredi Chiappelli, Edizione del Centenário, Milão, 1965, p. 793.

3 Dante, Op. cit., p. 794.

4 Dante, Op. cit., p. 794.

5 Dante, Op. cit., p. 794.
} 
Com efeito, estabelecido o poder temporal do monarca do mundo em termos laicos, Dante preocupa-se detidamente na candente questão da relação entre o Sacerdócio e o Império que tanto ocupou os filósofos medievais, desde S. Tomás de Aquino, João de Salisbúria, Marsílio de Pádua, Egídio Romano e Álvaro Pais, entre outros.

Dante ocupa-se privilegiadamente desta questão na Monarquia, pois, em 1300, ano do jubileu da cristandade, participando no governo da cidade de Florença, teve de opor-se à cúria romana que, em virtude da teoria da Plenitudo Potestatis do papa e com a eleição, em 1294, de Bonifácio VIII, manifestava sucessivos ensejos de intromissão no governo da cidade.

O ponto de partida para a análise desta questão aparece-nos nas páginas finais da Monarquia, com respeito ao duplo fim do homem:

«Dois fins deu ao homem a inefável Providência: a beatitude desta vida, que consiste no exercício da própria virtude e que se figura pelo paraíso terrestre; e a beatitude da vida eterna, que consiste na fruição da presença divina, à qual não pode ascender a virtude se não é ajudada pela luz divina, e que se entende pelo paraíso celeste» ${ }^{6}$

Dante já abordara esta questão em contexto diverso a propósito da vida activa e da vida contemplativa, de Marta e de Maria, bem como a propósito das relações entre a teologia e a filosofia, tal como atrás expusemos, a propósito do Convívio.

$\mathrm{Na}$ realidade, assim como a filosofia não é serva da teologia, também o poder temporal não é servo do poder espiritual, embora ambos colaborem na tarefa da salvação do homem, como Dante reconhece nas palavras finais da Monarquia e como tanto sublinha na Divina Comédia, através da personagem Beatriz. E assim como à beatitude terrestre, a que corresponde o poder do monarca do mundo, se chega por via da filosofia, por ela entendendo, sobretudo, as virtudes morais e intelectuais, assim também à beatitude celeste se chega por doutrinas espirituais que excedem a razão humana, sendo certo, todavia, que esta distinção não deve fazer-nos esquecer que «a felicidade mortal ordena-se, de certo modo, à felicidade imortal», devendo César ter por Pedro o respeito de um filho primogénito por seu pai. Por isto se entende que o poder temporal, em si mesmo e na sua natureza, não recebe do espiritual nem a existência nem a autoridade nem o seu exercício puro e simples, mas apenas aperfeiçoamento, no sentido em que age com maior eficácia pela luz da graça de Deus e pela bênção do Pontífice.

Então, sendo certo que o imperador não recebe a autoridade imperial das mãos do papa, entende Dante que a recebe imediatamente de Deus,

${ }^{6}$ Dante, Op. cit., p. 837. 
passando ao lado da tese escolástica da soberania inicial do povo. Esta é uma das teses nucleares do pensamento político de Dante. De facto, para os medievais, citando sempre palavras de S. Paulo (Rom. 13), o poder tinha origem em Deus. Mas tal tese referia-se amiúde à origem do poder em abstracto, pois S. Paulo, na Epístola aos Romanos, ao dizer que não havia poder que não viesse de Deus, referia-se ao poder em abstracto e não ao príncipe em concreto.

Então, a abordagem comum do problema da origem do poder encarava duas possibilidades: ou Deus o transmitia directamente ao rei, como transparecia da interpretação do Antigo Testamento a propósito de Saul e de David, ou através de um medianeiro, devendo considerar-se, neste caso, o povo ou o papa.

A mediação popular vingou entre os escolásticos de filiação tomista, pois S. Tomás expusera as bases teóricas em que tal teoria assentava, ao defender que o poder é uma faculdade constitutiva da comunidade humana, nela residindo, por ser natural que todas as entidades orientadas para um fim possuíssem as faculdades necessárias para o alcançar, e como a comunidade era uma entidade transpessoal dotada de fim próprio, o bem comum, deveria possuir em si própria as faculdades para o realizar.

Quanto à tese da mediação papal, sustentava-se, em boa medida, na tese de que Cristo legara a Pedro os dois gládios (Lucas, 31-34), símbolos do poder temporal e espiritual, entendendo alguns dos seus defensores que este poder existe no papa não em acto, como o espiritual, mas em hábito ou potência, sendo exercido através do imperador, mas podendo o Sumo Pontífice reduzi-lo a acto em certas circunstâncias. O gládio espiritual é desembainhado pelas mãos da Igreja, mas o gládio temporal, que Cristo ordenara fosse mantido por Pedro na bainha, deve ser aplicado em defesa da igreja pela mão dos soldados do rei, mas por ordem e autoridade do sumo pontífice.

Sucede que Dante se inclina para a tese de que o encargo da monarquia e do império provém imediatamente de Deus, preocupando-se em refutar as teses sobre a mediação papal.

A afirmação que poderia bem enquadrar toda a sua argumentação é elaborada por referência à fala de Cristo aos Apóstolos, quando lhes manda dar a César o que é de César e a Deus o que é de Deus, expressão mediante a qual Cristo legitimava o poder do império e o declarava não incompatível com a caridade e a religião. Diz então Dante:

«Devemos a Pedro tudo o que é de Pedro, mas não devemos a Pedro tudo o que é de Cristo» ${ }^{7}$

${ }^{7}$ Dante, Op. cit., p. 834. 
Queria isto dizer que Cristo não transmitira a Pedro a sua dupla realeza, legando-lhe apenas o gládio espiritual. Para além do mais, enquanto homem, não exerceu o poder régio temporal, tendo respondido a Pilatos que o seu reino não era deste mundo.

Não colhiam, por isso, os argumentos dos defensores da mediação papal e da autoridade da igreja em assuntos do foro temporal.

Não colhia, para Dante, o argumento de que Saul fora deposto pelo profeta Samuel, pois Samuel agira como ministro ou núncio e não como vigário de Deus, ou seja, agiu por ordem directa de Deus, ao passo que se agisse como vigário, qual é o papa, deveria possuir a faculdade de legislar e de julgar dentro dos limites de jurisdição própria, o que não fazia supor o texto bíblico ${ }^{8}$.

Rejeitava também, entre vários outros que enuncia com minúcia, o argumento baseado no significado das chaves de S. Pedro, bem como o dos dois gládios. No primeiro caso, o termo «tudo quanto ligares na terra» não deveria ser tomado em sentido absoluto, pois se distribui a uma matéria restrita, sendo certo que «sempre se deve ver como e a que se distribui um sinal universal, pois facilmente se verá a quanto a sua distribuição se estende, conhecida a natureza e o âmbito do termo distribuído, que é este: "Poderás ligar e desligar tudo quanto diga respeito ao teu ofício"»». Então, o sinal universal que se inclui em «tudo quanto», contrai-se na sua distribuição pelo ofício das chaves do reino dos céus, devendo concluir-se, diz Dante, que o Papa não pode ligar e desligar as leis do império.

Quanto à tese dos dois gládios, sempre bramida pelos defensores da plenitude do poder papal, considera Dante que «a intenção de Cristo manifesta-se aqui assaz claramente: não diz "comprai ou possui dois gládios, melhor doze, a fim de que cada um tivesse o seu"». O que Cristo pretendeu dizer, segundo a interpretação que Dante faz do célebre texto de Lucas foi que se cada um não puder possuir o seu gládio, dois eram suficientes. Não poderia por isso concluir-se que os dois gládios simbolizariam os dois poderes, estando ambos sob a jurisdição de Pedro.

Conclui então Dante que o poder do império, cujo objectivo é conduzir os homens para a felicidade temporal de acordo com as lições da filosofia, provém imediatamente de Deus, pois «como a disposição do mundo é a consequência da posição dos astros no firmamento, segue-se que para que as doutrinas de liberdade e paz sejam aplicadas adequadamente pelo curador do mundo aos diversos lugares e tempos, devem elas ser dispensadas por Aquele que presencialmente intui a total disposição dos céus. Este é o

8 Dante, Op. cit., p. 826.

9 Dante, Op. cit., p. 827. 
único que pré-ordenou o movimento dos astros a fim de que por essa mesma providência todas as coisas se reunissem nas várias ordens. Se é assim, só Deus elege, só Deus investe porque ele não tem superior. De onde se pode concluir que aqueles que hoje se chamam eleitores, ou aqueles que no passado receberam tal nome, não têm qualquer direito a esse título. Deverão chamar-se antes reveladores da providência divina» ${ }^{10}$. Ficando deste modo esclarecida, nos limites da sua tese, a realidade histórica da eleição do imperador pelos príncipes alemães.

\section{RESUMO}

Situamos Dante no contexto das polémicas medievais sobre a relação entre os poderes temporal e espiritual, em clara defesa das prerrogativas e da autonomia do poder temporal contra os partidários da teocracia. Neste contexto cumpre, por um lado, sublinhar a concepção da sociedade e da política como tendo por fim a actualização da potência específica do homem, ou seja, da faculdade ou virtude da intelecção, colocando, deste modo o poder numa base gnosiológica. Por outro lado, situando a questão da origem do poder fora das teses tradicionais da escolástica, Dante considera e defende a tese da origem divina imediata do poder, procurando, por essa via, sublinhar a sua autonomia perante as pretensões do Pontífice romano. É neste quadro que se entrega à análise criteriosa do «ofício das chaves» de São Pedro, limitando a sua extensão aos assuntos do foro espiritual, por devermos a Pedro tudo o que é de Pedro e por não devermos a Pedro tudo o que é de Cristo.

\section{RÉSUMÉ}

Nous situons Dante dans le contexte des polémiques médiévales sur la relation entre les pouvoirs temporel et spirituel, en défendant clairement les prérogatives et l'autonomie du pouvoir temporel contre les partisans de la théocracie. Dans ce contexte, il faut souligner, d'un côté, la conception de la société et de la politique ordonnées à l'actualisation de la puissance spécifique de l'homme, c'est à dire, de la faculté ou de la vertu de l'intellection, en plaçant ainsi le pouvoir sur une base gnosiologique. D'un autre côté, en plaçant la question de l'origine du pouvoir hors des thèses traditionnelles de la scholastique, Dante considère et défend la thèse de l'origine divine immédiate du pouvoir, essayant ainsi de souligner son autonomie face aux prétentions du Pontife romain. C'est dans ce cadre qu'il s'occupe de l'analyse rigoureuse de «l'office des clés» de Saint Pierre, en limitant son étendue aux affaires du for spirituel, parce qu'on doit à Pierre tout ce qui est à Pierre et parce qu'on ne doit pas à Pierre tout ce qui est au Christ.

10 Dante, Op. cit., p. 837. 